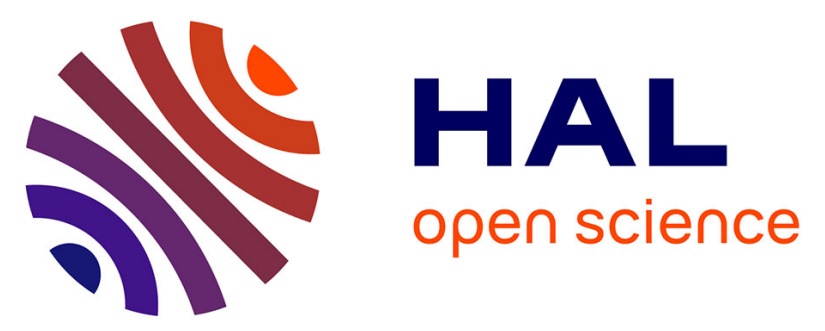

\title{
The Structure of Liquid Perfluoro Tert-Butanol using Infrared, Raman and X-Ray Scattering analyzed by Quantum DFT calculations and Molecular Dynamics
}

\author{
M. Isabel Cabaço, Marcel Besnard, Carlos Cruz, Pedro Morgado, Gonçalo
} M.C. Silva, Eduardo J.M. Filipe, João A.P. Coutinho, Yann Danten

\section{To cite this version:}

M. Isabel Cabaço, Marcel Besnard, Carlos Cruz, Pedro Morgado, Gonçalo M.C. Silva, et al.. The Structure of Liquid Perfluoro Tert-Butanol using Infrared, Raman and X-Ray Scattering analyzed by Quantum DFT calculations and Molecular Dynamics. Chemical Physics Letters, 2021, 779, pp.138844. 10.1016/j.cplett.2021.138844 . hal-03452084

\section{HAL Id: hal-03452084 https://hal.science/hal-03452084}

Submitted on 26 Nov 2021

HAL is a multi-disciplinary open access archive for the deposit and dissemination of scientific research documents, whether they are published or not. The documents may come from teaching and research institutions in France or abroad, or from public or private research centers.
L'archive ouverte pluridisciplinaire HAL, est destinée au dépôt et à la diffusion de documents scientifiques de niveau recherche, publiés ou non, émanant des établissements d'enseignement et de recherche français ou étrangers, des laboratoires publics ou privés. 


\title{
The Structure of Liquid Perfluoro Tert-Butanol using Infrared, Raman and X-Ray Scattering analyzed by Quantum DFT calculations and Molecular Dynamics.
}

\author{
M. Isabel Cabaço ${ }^{a, b 1}$, Marcel Besnard ${ }^{a, c}$, Carlos Cruz ${ }^{a, d}$, Pedro Morgado ${ }^{e}$, Gonçalo M. C. Silva ${ }^{e}$, \\ Eduardo J. M. Filipe ${ }^{\mathrm{e}}$, João A. P. Coutinho ${ }^{\mathrm{f}}$, Yann Danten ${ }^{\mathrm{c}}$ \\ ${ }^{a}$ CeFEMA, ${ }^{d}$ Department of Physics and ${ }^{e}$ Centro de Química Estrutural, Instituto Superior Tecnico, \\ Universidade de Lisboa, Av. Rovisco Pais 1, 1049-001 Lisboa, Portugal \\ ${ }^{b}$ Laboratory of Instrumentation, Biomedical Engineering and Radiation Physics (LIBPhys-UNL), \\ Department of Physics, NOVA School of Science and Technology, NOVA University Lisbon, 2829-516 \\ Caparica, Portugal \\ ${ }^{c}$ GSM Institut des Sciences Moléculaires, CNRS (UMR 5255), Université Bordeaux I, 351, Cours de \\ la Libération 33405 Talence Cedex, France \\ ${ }^{f}$ CICECO, Departamento de Química, Universidade de Aveiro 3810-193 Aveiro, Portugal
}

\begin{abstract}
The state of aggregation of room temperature liquid perfluoro tert-butanol (TBF) has been assessed in comparison with that of its hydrogenated homologue (TBH). This study has been performed using vibrational spectroscopy (Raman scattering and infrared absorption) and Xray diffraction, analyzed by quantum DFT calculations and Molecular Dynamics simulations. In contrast with $\mathrm{TBH}$, in which large oligomers (aggregates of 4 to 6 molecules) predominate, TBF was found to mainly consist of monomers and dimers. The strongly acidic properties of this molecule, due to the electron-withdrawing effect of its $\mathrm{CF}_{3}$ groups, plays a relevant role in making it a poorly associated alcohol.
\end{abstract}

\section{INTRODUCTION}

The structure of room temperature liquid tert-butanol $\left(\mathrm{CH}_{3}\right)_{3} \mathrm{COH},(\mathrm{TBH})$, has been widely studied both experimentally [1-17] and theoretically [12-15,18-21]. From these studies, it appears that TBH presents a rather structured liquid phase consisting of coexisting monomers, dimers, cyclic tetramers and hexamers. The population of tetramers and hexamers is found to dominate and represent about $65 \%$ of the total species [8-9]. These species form small reverse micelles-like aggregates of 4 to 6 molecules (cyclic hexamer) $[12,20,21]$ in which the $\mathrm{OH}$ groups of the molecules involved in hydrogen-bonding form a core, surrounded by the methyl groups facing outwards $[13,14]$. Spatial correlations between these neighboring aggregates have also been evidenced [9].

\footnotetext{
${ }^{1}$ Corresponding author: M. Isabel Cabaço, e-mail: isabelcabaco@tecnico.ulisboa.pt
} 
In marked contrast, investigations of the structure of liquid perfluoro tert-butanol $\left(\mathrm{CF}_{3}\right)_{3} \mathrm{COH}$, (TBF), are scarce [22-24]. These studies have been only performed with vibrational spectroscopy in vapor, liquid, low temperature matrices and in dilution to attribute the characteristic frequency of the vibrations of the different molecular aggregates. The spectra of liquid TBF were assigned, and it was concluded that it is a poorly associated liquid in which monomers and dimers coexist. The monomers are predominant and their population was roughly estimated to be $70-80 \%$ [22]. These experimental studies were reported a long time ago and came to this conclusion, using qualitative arguments lacking in quantitative insights. It is noteworthy that such a conclusion is consistent with the fact that the molecule of TBF has stronger acidic properties $(\mathrm{pKa}=5.4)$ [25] than TBH $(\mathrm{pKa} \sim 19)$ [26] due to the electronwithdrawing effect of its $\mathrm{CF}_{3}$ groups [27]. This strong proton-donor character leads to a weak tendency for self-association of the molecules. In addition, the larger volume of the $\mathrm{CF}_{3}$ groups, compared to $\mathrm{CH}_{3}$ in $\mathrm{TBH}$, results in a large stereochemical hindrance, preventing the formation of sequential hydrogen bonding and aggregation beyond the dimer. The analysis of the structure of liquid TBF remains, up to now, at a rather qualitative level.

Therefore, we have decided to revisit the structure of liquid TBF using an experimental multi-technic approach combining vibrational spectroscopy (infrared absorption and Raman scattering) and X-Ray diffraction with a theoretical analysis involving quantum DFT calculations and Molecular Dynamics (MD) simulations. The aim of this study is to provide comprehensive quantitative information on the structure of TBF using the tools existing nowadays.

\section{EXPERIMENTAL CONDITIONS}

The TBF and TBH (Apollo and Sigma-Aldrich, respectively, purity greater than 99\%) were dried using molecular sieves ( $3 \AA$ ). The water content was measured by Karl-Fisher titration and found to be $400 \mathrm{ppm}$.

Raman and infrared spectra were collected with a resolution of $4 \mathrm{~cm}^{-1}$ on a Horiba JobinYvon XploRA and on a Bruker-Alpha FT-IR spectrometer. X-ray diffraction patterns were recorded in a range of momentum transfer $\mathrm{Q}$ from 0.15 to $2 \AA^{-1}$. All the experiments were performed at 298 K. Experimental details are given in Supplementary Material (SM.1).

The structure and spectral features of monomers, dimers and trimers of TBF molecules have been assessed by DFT calculations including using the Gaussian16.C01 package [28]. Details of the calculations are reported in the SM.2. 
Molecular dynamics simulations were performed using the GROMACS 5.0.7 Software [29] with molecular models based on the atomistic OPLS-AA force field [30]. The intramolecular and dispersive interaction parameters were taken from the literature [30-33], and the atomic partial charges were derived in this work from $a b$ initio calculated electron density distributions using the CHELPG method [34]. The detailed description of the molecular models used and the simulation procedure is given in the SM.3.

\section{EXPERIMENTAL RESULTS}

\subsection{Vibrational Spectroscopy}

\subsubsection{Vibrational spectra of the $v_{O H}$ stretching vibration}

The infrared and Raman spectra of the $v_{\mathrm{OH}}$ stretching vibration of liquid TBF and $\mathrm{TBH}$ are displayed in Figure 1.

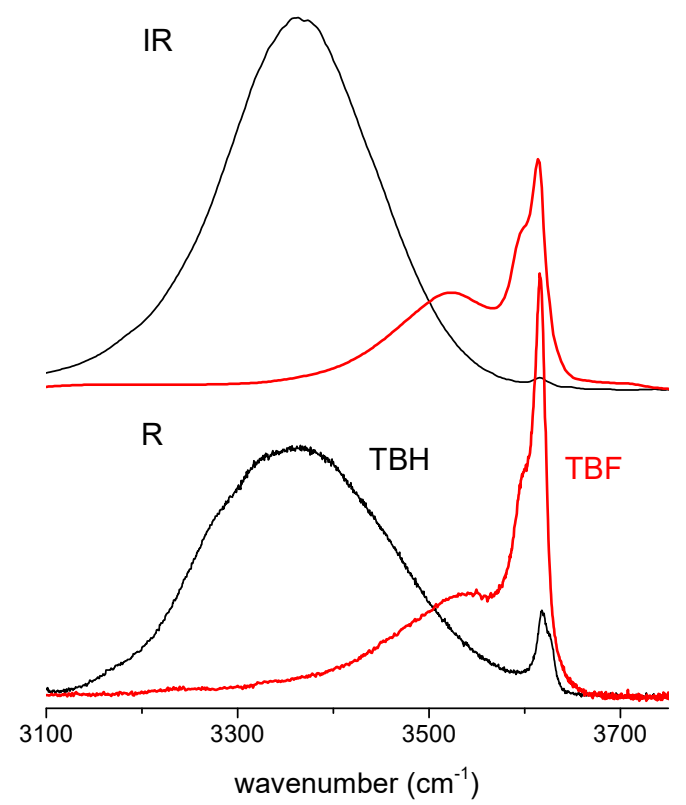

Figure 1. Infrared and Raman spectra of the $v_{\mathrm{OH}}$ stretching vibration of TBF (red) and TBH (black). The Raman spectrum of TBH has been corrected from combination bands using deuterated tert-butanol (See SM.4).

For each alcohol, the infrared and Raman spectra are very similar. However, the spectra are markedly different for the two compounds. In $\mathrm{TBH}$, the spectra present an intense, broad and featureless band assigned to oligomers (linear dimers and cyclic tetramers and hexamers) $[5,6]$ accompanied at higher frequency by a weak composite band (assigned to monomers and the end chain of linear dimers). In contrast, the spectra of TBF exhibits an intense and narrow 
component (circa $3615 \mathrm{~cm}^{-1}$ ), having a doublet like structure, accompanied by a broad shoulder. These observations already allow concluding that the local ordering in TBF is very different from that existing in TBH and will mostly involve monomers and small aggregates. The analysis of the band shapes of TBF spectra based upon fitting experimental profiles shows that at least three Gaussian components are needed to achieve a good fit in both spectroscopies (Figure 2, Table 1). They are assigned to monomer (M), non-bonded end groups (Dim A) and bonded OH groups (Dim D) of dimers. Other minor contributions can be considered and assigned to trimers (Trim) (Table 1).
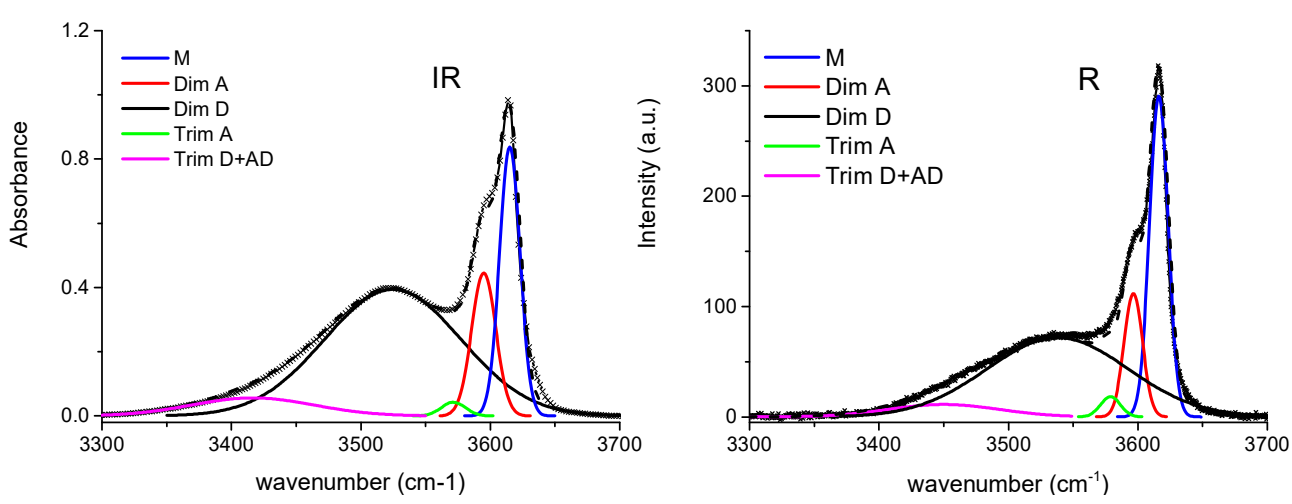

Figure 2. Band-shape analysis of the $v_{\mathrm{OH}}$ stretching band of TBF using Gaussian profiles: infrared (left) and Raman (right). The sum of the fitted profiles (dash line) is compared with the experimental spectra $(-\times-)$.

The structure and stabilization energy of these species have been obtained from DFT calculations (details in SM.2, Table SM.1). The calculated band center frequencies of the $v_{\mathrm{OH}}$ vibration of these species are reported in Table 1 . The calculated vibrational transitions are found rather close to the experimental ones, supporting the previous assignments.

The population of monomers and oligomers was estimated by dividing the experimental integrated intensities of the fitted Gaussian profiles by the IR and Raman activities calculated by DFT (Table 1). The analysis of the infrared and Raman data leeds to consistent results on the speciation of the alcohol. The fraction of monomers is found to be about $64 \%$ and that of linear dimers (which constitute the main contribution of oligomers species) is about $33 \%$. Higher oligomers consisting of linear trimers have an almost negligible population of about $3 \%$. Finally, these results show that TBF is a poorly associated alcohol compared with TBH.

TABLE 1. Experimental band centre frequencies and full widths of the fitted Gaussian profiles of IR and Raman spectra of liquid TBF at room temperature. DFT scaled frequency values for monomers, dimers and linear trimers are reported (scaling factor 0.9525, cf. details of DFT calculations in SM.2). The relative population of the different species were obtained using the experimental integrated 
intensities of the fitted Gaussian profiles divided by the calculated activities at B3LYP/6-311+G(2d,p) level.

\begin{tabular}{|c|c|c|c|c|c|c|c|c|}
\hline $\begin{array}{c}\text { Experimental } \\
\text { IR frequency } \\
\left(\mathrm{cm}^{-1}\right)\end{array}$ & \begin{tabular}{|c|} 
FWHH \\
$\left(\mathrm{cm}^{-1}\right)$
\end{tabular} & $\begin{array}{c}\text { IR } \\
\text { Activity } \\
\text { (km/mol) }\end{array}$ & $\begin{array}{c}\text { Relative } \\
\text { population } \\
\text { (Infrared) }\end{array}$ & $\begin{array}{l}\text { Scaled frequency } \\
\left(\mathrm{cm}^{-1}\right)\end{array}$ & \begin{tabular}{|c|} 
Experimental \\
Raman \\
frequency \\
$\left(\mathrm{cm}^{-1}\right)$
\end{tabular} & $\begin{array}{l}\text { FWHH } \\
\left(\mathrm{cm}^{-1}\right)\end{array}$ & $\begin{array}{l}\text { Raman } \\
\text { Activity } \\
\left(\AA^{4} / \mathbf{a m u}\right)\end{array}$ & \begin{tabular}{|c|} 
Relative \\
population \\
(Raman)
\end{tabular} \\
\hline 3615 & 18 & 90.3 & 0.65 & $\begin{array}{c}3613 \\
\text { Monomers (M) }\end{array}$ & 3616 & 17 & 51.1 & 0.63 \\
\hline 3595 & 22 & 122.1 & \multirow{2}{*}{0.32} & $\begin{array}{c}3584 \\
\text { Open end Dimers } \\
(\text { Dim A })^{\S}\end{array}$ & 3597 & 17 & 34.3 & \multirow{2}{*}{0.34} \\
\hline 3525 & 124 & 574.6 & & $\begin{array}{c}3489 \\
\text { Dimers (Dim D) }\end{array}$ & 3538 & 128 & 197.7 & \\
\hline 3571 & 22 & 117.9 & \multirow[t]{2}{*}{0.03} & $\begin{array}{c}3582 \\
\text { Linear trimers end } \\
(\text { Trim A) }\end{array}$ & 3579 & 18 & 34.9 & \multirow[t]{2}{*}{0.03} \\
\hline 3416 & 111 & $\begin{array}{l}609.3 \\
450.3\end{array}$ & & $\begin{array}{c}3432(\text { Trim D) } \\
3518(\text { Trim AD) } \\
\text { Linear trimers }\end{array}$ & 3450 & 100 & $\begin{array}{l}168.6 \\
133.3\end{array}$ & \\
\hline
\end{tabular}

${ }^{\S}$ A-proton acceptor, D-proton donor and AD-proton acceptor and donor of the hydroxyl group

\subsubsection{Vibrational spectra of the $\gamma_{O H}$ out of plane vibration}

The $\gamma_{\mathrm{OH}}$ out of plane vibration of TBH was reported at about $250 \mathrm{~cm}^{-1}$ for monomers in low temperature matrices $(10 \mathrm{~K})$ and at about $640 \mathrm{~cm}^{-1}$ for TBH diluted in carbon tetrachloride [1]. In liquid TBH, this vibration gives rise to a broad band centered at about $635 \mathrm{~cm}^{-1}$ in infrared spectroscopy (Figure 3). The large value of this blue shift together the Gaussian line shape and large full-width (about $170 \mathrm{~cm}^{-1}$ ) of this band are the spectral signatures of the presence of hydrogen-bonded molecules.

The Gaussian band shape may suggest that the profile is in-homogeneously broadened and reflects a rather static distribution (on the time-scale of the experiment) of the out of plane vibrations of the species. In marked contrast, this band is absent in Raman spectroscopy due to its low activity. This apparent difference could be somehow anticipated as it is well established that for hydrogen bonded systems like alcohols, Raman spectroscopy is more sensitive to the presence of monomers whereas infrared spectroscopy is more sensitive for the detection of associated species [35].

For TBF in gaseous phase, the $\gamma_{\mathrm{OH}}$ vibration of non-bonded $\mathrm{OH}$ end groups was reported at about $252 \mathrm{~cm}^{-1}$ in infrared spectroscopy [22]. In liquid phase, if this vibration was affected by the association, it would appear in the spectral domain $600-800 \mathrm{~cm}^{-1}$. The absence of this feature allows concluding that either it is not affected by hydrogen bonding or it's activity is too low to be detected (Figure 3). 


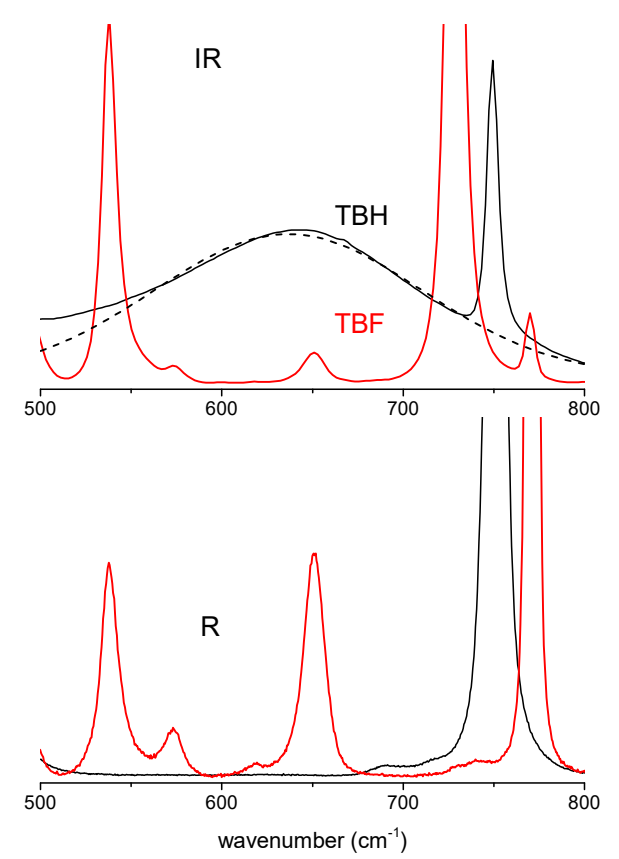

Figure 3. Infrared and Raman spectra of TBF (red) and TBH (black). The $\gamma_{\mathrm{OH}}$ out of plane vibration is only observed for TBH in IR and fitted by a broad Gaussian profile (dash line). The assignment of the other bands is given in SM.4.

\subsubsection{Vibrational spectra of the $\delta_{\mathrm{OH}}$ in plane bending vibration}

The $\delta_{\mathrm{OH}}$ bending (in plane vibration) situated at $1382 \mathrm{~cm}^{-1}$ in gaseous phase should be shifted towards higher wavenumber by about $70 \mathrm{~cm}^{-1}[1,36]$ due to the molecular aggregation in liquid phase. However, this band is observed at about the same frequency $\left(1380 \mathrm{~cm}^{-1}\right)$ showing that molecular association in TBF is very weak (SM.4, figure SM.4).

The results obtained on the $\gamma_{\mathrm{OH}}$ out of plane and on the $\delta_{\mathrm{OH}}$ bending vibrations provide further support on the conclusion reached from the study of the $v_{\mathrm{OH}}$ stretching vibration that TBF is a poorly associated alcohol.

\subsection{X-ray diffraction}

The X-ray diffraction patterns of the TBF and TBH are compared in Figure 4. For TBH two diffraction peaks are observed at momentum transfer $Q$ of about $0.7 \AA^{-1}$ and $1.3 \AA^{-1}$. These values are consistent with those reported by Morineau et al [9] for the static structure factor obtained by neutron diffraction. The pre-peak at $0.7 \AA^{-1}$ has been interpreted as resulting from the existence of an intermediate range ordering between adjacent cyclic clusters. The main peak at $1.3 \AA^{-1}$ results from intermolecular and intramolecular scattering contributions. In TBF the pre-peak is absent showing that the local organization existing in TBH due to 
hydrogen bonding molecules does not occur in TBF. Therefore, it can be inferred that the whole atomic distribution is as random as for nonhydrogen bonded molecular liquids.

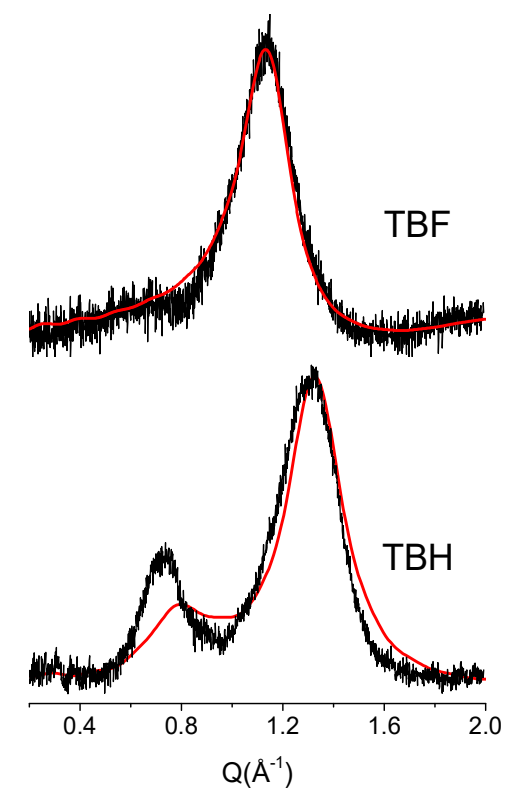

Figure 4. Experimental (black) and calculated (red) X-ray diffraction patterns of liquid TBF (top) compared with TBH (bottom).

In conclusion, vibrational spectroscopic experiments combined with diffraction measurements show that in TBF monomers and dimers are dominant and that the proportion of higher oligomers is negligible. This conclusion is in marked contrast with TBH in which the population of larger oligomers is dominant.

\section{MOLECULAR DYNAMICS RESULTS}

The local structure of liquid $\mathrm{TBF}$ and $\mathrm{TBH}$ can be discussed from the calculated intermolecular radial distribution functions ( $\mathrm{rdf}$ ) displayed in Figure 5. For TBH, the rdf $\mathrm{g}_{\mathrm{H} \ldots \mathrm{O}}$ between the donor hydrogen with the acceptor oxygen atoms of the interacting molecules displays a very intense peak at short distances ( $c a .0 .2 \mathrm{~nm}$ ), showing that the hydrogen bonding interaction is a dominant factor in the short-range structuration of this alcohol. In contrast, this rdf is much weaker in TBF and remains smaller than 1.0 up to distances comparable to the molecular diameter. This fluid presents a much weaker local structure, and also a lower degree of hydrogen bonding than TBH. Looking at the partial charges of the models used, the charge difference between the two atoms of the hydroxyl group, although significant, is indeed lower in TBF (0.901 e) than in TBH $(1.131 \mathrm{e})$, thus giving to the TBF model a weaker hydrogen bonding character (Table SM.2). The unusually low degree of 
hydrogen bonding in TBF may also stem from the stereochemical impediment effect of the bulky $\mathrm{CF}_{3}$ groups.
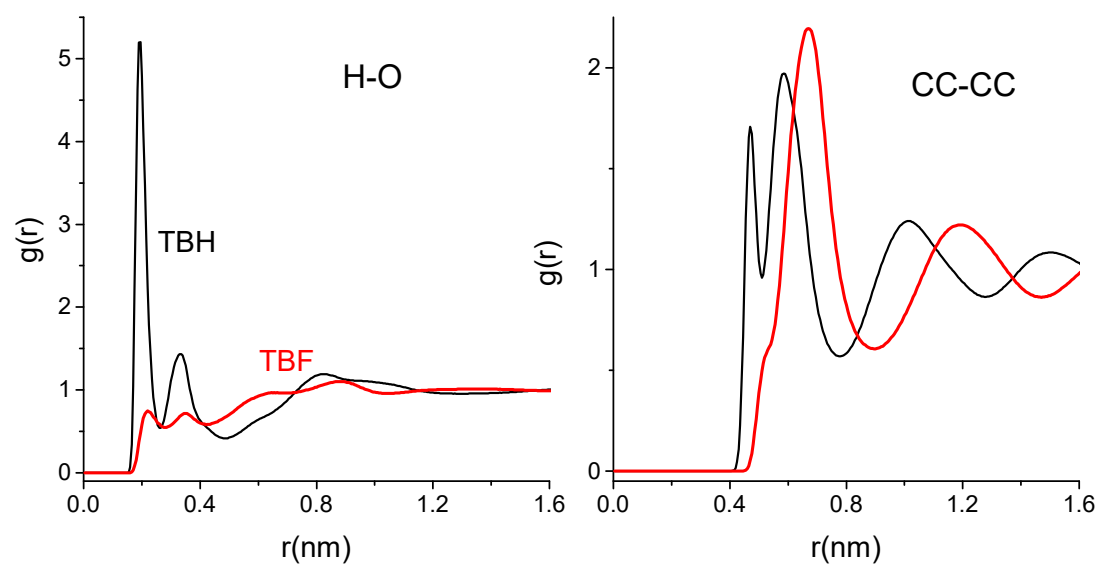

Figure 5. Intermolecular radial distribution functions for TBH (black) and TBF (red): $\mathrm{g}_{\mathrm{H} \ldots \mathrm{O}}$ between the donor hydrogen and the acceptor oxygen atoms of hydroxyl groups (left); $\mathrm{g}_{\mathrm{CC}} \cdots_{\mathrm{CC}}$ between the central carbon (CC) atoms (right).

The rdfs between the central carbon (CC) atoms in both alcohols are also quite different with TBH clearly displaying two peaks at short distances (ca. 0.47 and $0.58 \mathrm{~nm}$ ) whereas a higher single intense peak $(0.67 \mathrm{~nm})$ with a small shoulder is observed in TBF. This indicates that TBH is a much more 'structured' fluid (at shorter distances), showing at least two preferential geometries of interaction between adjacent molecules, whereas the CC...CC $\mathrm{rdf}$ of TBF is less structured and resembles the rdf of non-hydrogen bonded molecular fluids.

The x-ray diffraction patterns of both alcohols have also been calculated from the molecular dynamics trajectories, using the TRAVIS software [37], for 3000 molecules. The calculated patterns reproduce the experimental results, validating the molecular models used in MD simulations (Figure 4). Although the structural interpretation previously proposed is strongly supported, the X-Ray results suggest that liquid TBH has a somewhat higher degree of supramolecular ordering than predicted by the model used in the MD simulations.

The simulation trajectories have been further analyzed to characterize and quantify the hydrogen bonded aggregates, which were identified in the spectroscopic study. Thus, we have implemented an analysis algorithm using the following criterion: two molecules are neighbors and belong to the same aggregate if the hydroxyl hydrogen of one of them is closer than $0.27 \mathrm{~nm}$ to the oxygen atom of the other. The algorithm identifies the size of all aggregates in the analyzed configurations and, for each size, how many aggregates are-cyclic 
(all molecules of the cyclic aggregate have exactly two neighbors), linear (two molecules of the aggregate have 1 neighbor and all others have two neighbors) and finally neither cyclic nor linear (typically corresponding to ramified or lasso-type aggregates).

The distribution of aggregate sizes is seen in Figure 6, where the probability $\mathrm{p}(\mathrm{n})$ of finding a molecule in an aggregate of size $\mathrm{n}$ is plotted as a function of $\mathrm{n}$. This probability is defined as:

$$
p(n)=\frac{\sum_{k} n \cdot s(n, k)}{\sum_{m} \sum_{k} m \cdot s(m, k)}
$$

where $s(n, k)$ represents the number of aggregates of size $n$ in the configuration $k$. The average aggregation number was found to be 3.97 for $\mathrm{TBH}$ and 1.17 for $\mathrm{TBF}$, showing that almost all TBF molecules are found as monomers.

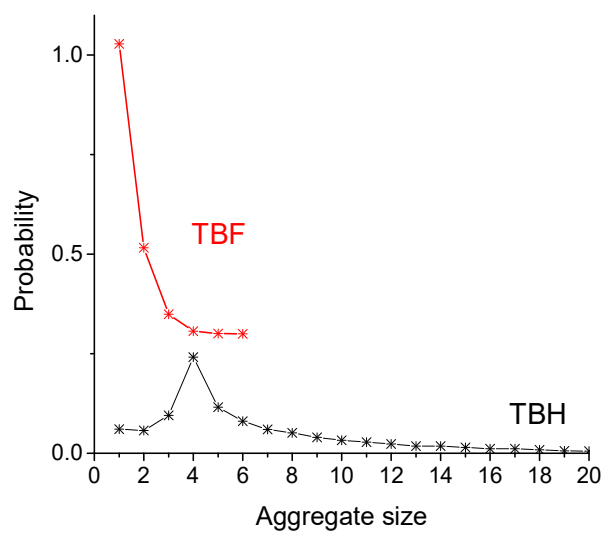

Figure 6. Probability of finding a molecule in a hydrogen bonded aggregate of size $n$, for TBF (red) and TBH (black), determined from Molecular Dynamics. The TBF data set is displaced vertically for clarity $(+0.3)$.

In $\mathrm{TBH}$, it can be seen that there is a clear preference for the formation of tetramers, which account for about $24 \%$ of the molecules. The distribution of aggregate sizes is quite broad, with $20 \%$ of the molecules belonging to aggregates of size 10 or larger; the number of monomers and dimers is also noticeable, with around 6\% probability each. These results essentially agree with the study of Perera et al. [20,21], despite the differences in the TBH model used and in the criteria used for identification of clusters. Between sizes 3 and 7, a significant number of cyclic aggregates can be identified, and in the case of tetramers they constitute the majority $(61 \%)$. This makes the cyclic tetramer the most common topology of aggregates in $\mathrm{TBH}$, accounting for $15 \%$ of the alcohol molecules. 
TBF displays a very different type of aggregation behavior in which most molecules are found as monomers (73\%). The probability of finding molecules belonging to dimers and trimers is $22 \%$ and $5 \%$, respectively, and larger aggregates are almost inexistent. These results lead to proportions of monomer, dimer and trimer aggregates which are of about $85 \%$, $13 \%$ and $2 \%$, respectively (Table SM.3).

These differences in aggregation behavior are clearly illustrated in Figure 7, which shows partial simulation snapshots of the two liquid alcohols. It can be seen that TBH (left) predominantly displays hydrogen bonded aggregates with 3 or more molecules, whereas the TBF molecules (right) typically appear as monomers or dimers.
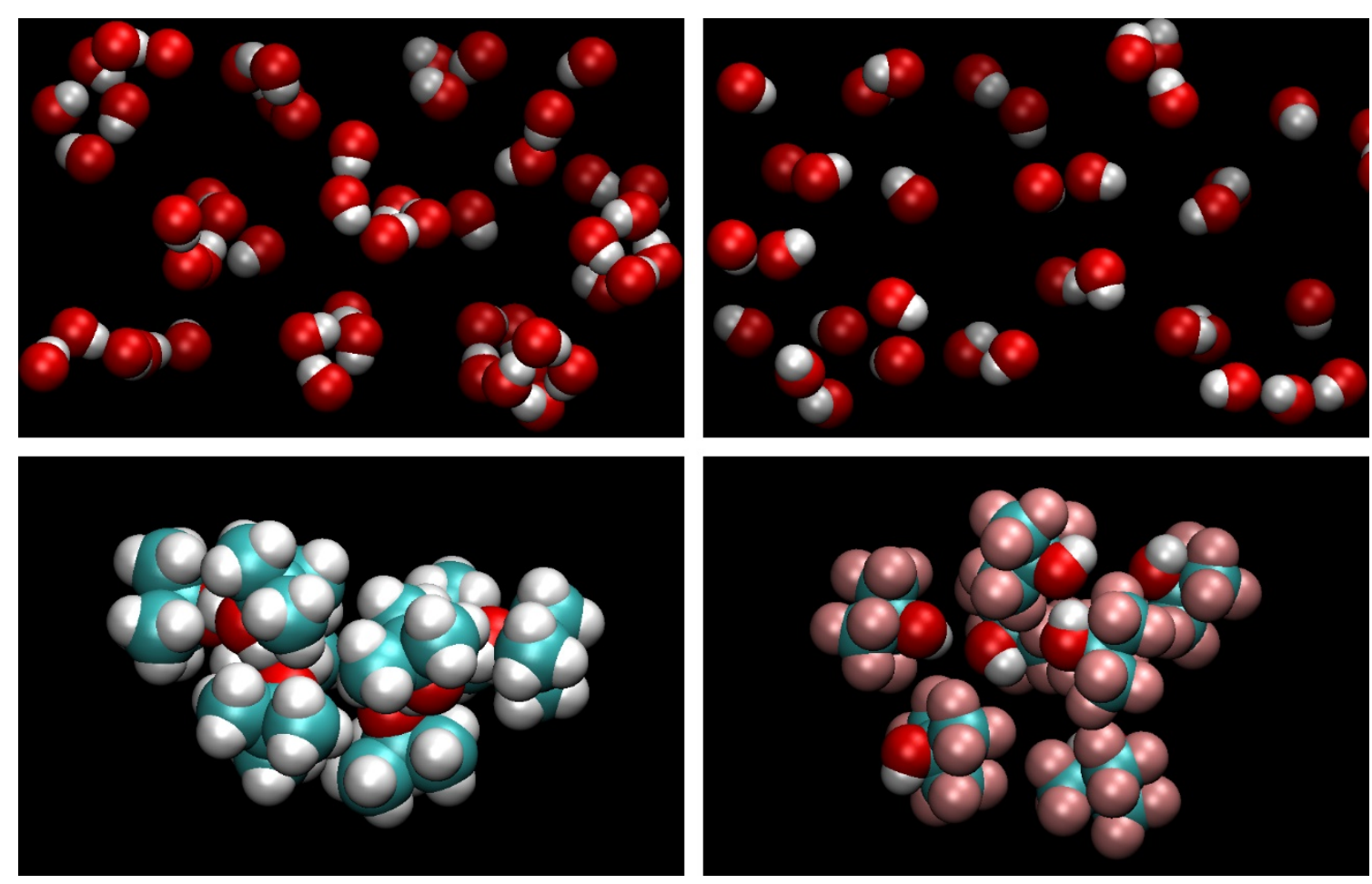

Figure 7. Top) Simulation snapshots of approximately equal volumes of TBH (left panel) and TBF (right panel); for the sake of clarity, only the hydroxyl groups are represented. Bottom) selected parts of the same snapshots, with all atoms represented, highlighting two adjacent micelle-like aggregates of TBH (left) and 5 monomers and a dimer of TBF (right).

The populations of the species obtained from the analysis of spectral data combined with DFT, or more directly by Molecular Dynamics, although not being strictly the same as a result of the specific problematic involved in the theoretical approaches are nevertheless close. We conclude that there is no doubt about the speciation of TBH as essentially 
consisting of a large monomer population ( $75 \%)$, coexisting with a smaller fraction of dimer $(\sim 23 \%)$.

\section{CONCLUSION}

It has been shown quantitatively that TBF is a poorly associated liquid at room temperature. The liquid phase mainly consists of monomers and dimers. Higher oligomers, consisting of trimers, are almost negligible. The structure of this liquid phase, which is drastically different than that of the micellar-like $\mathrm{TBH}$, is the consequence of the strong acidic character of TBF $(\mathrm{pKa}=5.4)$ compared to the more basic one of TBH $(\mathrm{pKa} \sim 19)$. Finally, this study (based on a combined experimental multi-technique approach with DFT calculations and Molecular Dynamics), confirms the qualitative conclusions based on vibrational spectroscopy of older studies, providing quantitative information on the structure of the liquid phase.

\section{Acknowledgements:}

The authors are pleased to thank Professor Laura Ilharco, Marta Coelho and Dr. Thierry Buffeteau for providing infrared facilities. We are indebted to Professor Jack Yarwood for critically reading the manuscript and for his comments.

The authors gratefully acknowledge the support provided by the HPC resources and allocations of computing time from GENCI (IDRIS) and the facilities of the Mesocentre de Calcul Informatique Aquitain (MCIA) of the University of Bordeaux and des Pays de l'Adour. This work was partly developed within the scope of the project CICECO-Aveiro Institute of Materials, UIDB/50011/2020 \& UIDP/50011/2020, financed by national funds through the FCT/MEC and when appropriate co-financed by FEDER under the PT2020 Partnership Agreement.

The authors also acknowledge financial support from FCT through CeFEMA strategic projects UID/CTM/04540/2013 and UID/CTM/04540/2019; and European Union and FCT through Grant M-ERA-NET2/0006/2016 (CellColor). 


\section{References}

1. J. Korppi-Tommola, Association of tert-Butyl Alcohol: a Matrix Infrared Study, J. Mol. Struct. 40 (1977) 13-23.

2. J. Korppi-Tommola, Tert-Butyl Alcohol - Matrix I.R. Spectra and Vibration Assignment, Spectrochimica Acta 34A (1978) 1077-1085.

3. G. Larsen and Z. K. Ismail, Monomeric tert-Butanol in Benzene and Cyclohexane Solutions: a Fourier-Transform Infrared Spectroscopy Study, J. Sol. Chem. 27, (1998) 901-909.

4. P. K. Kipkemboi, P. C. Kiprono and J. J. Sanga, Vibrational Spectra of t-Butyl Alcohol, t-Butylamine and t-Butyl Alcohol + t-Butylamine Binary Liquid Mixtures, Bull. Chem. Soc. Ethiop. 17 (2003) 211-218.

5. J-M. Andanson, J-C. Soetens, T. Tassaing and M. Besnard, Hydrogen Bonding in Supercritical tert-Butanol Assessed by Vibrational Spectroscopies and Molecular Dynamics Simulations, J. Chem. Phys. 122 (2005) 174512-9.

6. J-M. Andanson, 'Étude de la liaison hydrogène par spectroscopie vibrationnelle et simulation de dynamique moléculaire d'alcools en condition supercritique', Thesis, Université Bordeaux I (2005).

7. F. Palombo, M. Paolantoni, P. Sassi and A. Morresi, Spectroscopic studies of the "free" OH stretching bands in liquid alcohols, J. Mol. Liq. 125 (2006) 139-146.

8. P. Sassi, F. Palombo, R. S. Cataliotti, M. Paolantoni and A. Morresi, Distributions of HBonding Aggregates in tert-Butyl Alcohol: The Pure Liquid and Its Alkane Mixtures, J. Phys. Chem. A 111, (2007) 6020-6027.

9. A. R. Abdel Hamid, R. Lefort, Y. Lechaux, A. Moréac, A. Ghoufi, C. Alba-Simionesco and D. Morineau, Solvation Effects on Self-Association and Segregation Processes in tert-Butanol - Aprotic Solvent Binary Mixtures, J. Phys. Chem. B 117 (2013) 1022110230.

10. A. H. Narten and S. I. Sandler, X-ray diffraction study of liquid tertiary butyl alcohol at $26{ }^{\circ}$ C, J. Chem. Physics 71 (1979) 2069-2073

11. S. Sarkar, P. P. Nath and R. N. Joarder, Orientation Correlation versus Cluster Correlation in Molecular Liquids-signature through diffraction data, Phys. Letts. A 275 (2000), 138141

12. D. Zimmermann, T. Haber, H. Schaal and M. Suhm, Hydrogen bonded rings, chains and lassos: the case of t-butyl alcohol clusters, Mol. Phys. 99 (2001) 413-425.

13. D. T. Bowron, J. L. Finney and A. K. Soper, The Structure of Pure Tertiary Butanol, Mol. Phys. 93 (1998) 531-543.

14. P. P. Nath, S. Sarkar, P. S. R. Krishna and R. N. Joarder, Molecular Conformation and Structural Correlations of Liquid D-tert-Butanol at Room Temperature by Neutron Diffraction, Z. Naturforsch. 56a (2001) 825-831.

15. P. P. Nath, S. Sarkar, P. S. R. Krishna and R. N. Joarder, Intermolecular structure of liquid D-tert-butanol by neutron-diffraction data, Appl. Phys. A 74 (2002) S348-S351.

16. M. Saunders and J. B. Hyne, Trimeric Association of $t$-Butanol by NMR, J. Chem. Phys. 29 (1958) 253.

17. A.R. Yonker, S. L. Wallen, B. J. Palmer and B. C. Garrett, Effects of Pressure and Temperature on the Dynamics of Liquid tert-Butyl Alcohol, J. Phys. Chem. A 101 (1997) 9564-70. 
18. A. Karmakar, S. Sarkar and R. Joarder, Molecular Clusters in Liquid tert-Butyl Alcohol at Room Temperature, J. Phys. Chem. 99 (1995) 16501-16503.

19. P. G. Kusalik, A. P. Lyubartev, D. L. Bergman and A. Laaksonen, Computer Simulation Study of tert-Butyl Alcohol. I. Structure in the Pure Liquid, J. Phys. Chem. B 104 (2000) 9526-9532.

20. A. Perera, F. Sokolic and L. Zoranic, Microstructure of neat alcohols, Phys. Rev. E. 75 (2007) 060502(R) 1-4.

21. L. Zoranic, F. Sokolic and A. Perera, Microstructure of neat alcohols: A molecular dynamics study, J. Chem. Phys. 127 (2007) 024502-10.

22. J. Murto, A. Kivinen, J. Korppi-Tommola, R. Viitala, J. Hyomaki, Infrared and Raman Spectra of the Perfluorinated t-Butyl Alcohols $\left(\mathrm{CF}_{3}\right)_{3} \mathrm{COH}$ and $\left(\mathrm{CF}_{3}\right)_{3} \mathrm{COD}$, Acta Chem. Scand. 27 (1973) 107-120.

23. L. Schriver and A. Burneau, Infrared Spectroscopic Study of Intermolecular Effects on the Conformational Isomerism of Monomer and Dimer Perfluoro-t-buryl Alcohol in Mixed Matrices, J. Chem. Soc. Faraday Trans. 281 (1985) 503-516.

24. A. P. Luck and S. Peil, IR Studies of Van der Waals Interactions on Perfluoro-t-Butyl Alcohol OH. I. Environments Effects on Monomeric OH* and Self-Associates, J. Mol. Struct. 224 (1990) 175-184.

25. L. Knunyants and B. L. Dyatkin, Izv. Akad. Nauk. USSR, Chem. Ser. 923 (1964).

26. A. P. Serjeant and B. Dempsey, IUPAC Chemical Data Series 23, 989, Pergamon Press, NewYork (1979).

27. A. Vuluga, J. Legros, B. Crousse, A. M. Z. Slawin, C. Laurence, P. Nicolet and D. Bonnet-Delpon, Influence of the structure of Polyfluorinated Alcohols on Brønsted Acidity/Hydrogen-Bond Donor Ability and Consequences on the Promotor Effect, J. Org. Chem. 76 (2011) 1126-1133.

28. Gaussian 16, Revision C.01, Frisch, M. J.; Trucks, G. W.; Schlegel, H. B.; Scuseria, G. E.; Robb, M. A.; Cheeseman, J. R.; Scalmani, G.; Barone, V.; Petersson, G. A.; Nakatsuji, H.; Li, X.; Caricato, M.; Marenich, A. V.; Bloino, J.; Janesko, B. G.; Gomperts, R.; Mennucci, B.; Hratchian, H. P.; Ortiz, J. V.; Izmaylov, A. F.; Sonnenberg, J. L.; Williams-Young, D.; Ding, F.; Lipparini, F.; Egidi, F.; Goings, J.; Peng, B.; Petrone, A.; Henderson, T.; Ranasinghe, D.; Zakrzewski, V. G.; Gao, J.; Rega, N.; Zheng, G.; Liang, W.; Hada, M.; Ehara, M.; Toyota, K.; Fukuda, R.; Hasegawa, J.; Ishida, M.; Nakajima, T.; Honda, Y.; Kitao, O.; Nakai, H.; Vreven, T.; Throssell, K.; Montgomery, J. A., Jr.; Peralta, J. E.; Ogliaro, F.; Bearpark, M. J.; Heyd, J. J.; Brothers, E. N.; Kudin, K. N.; Staroverov, V. N.; Keith, T. A.; Kobayashi, R.; Normand, J.; Raghavachari, K.; Rendell, A. P.; Burant, J. C.; Iyengar, S. S.; Tomasi, J.; Cossi, M.; Millam, J. M.; Klene, M.; Adamo, C.; Cammi, R.; Ochterski, J. W.; Martin, R. L.; Morokuma, K.; Farkas, O.; Foresman, J. B.; Fox, D. J. Gaussian, Inc., Wallingford CT, 2016.

29. D. Van Der Spoel, E. Lindahl, B. Hess, G. Groenhof, A. E. Mark, H. J. C. Berendsen, GROMACS: fast, flexible, and free, J. Comput. Chem. 26 (2005) 1701-1718.

30. W. L. Jorgensen, D. S. Maxwell, J. Tirado-Rives, Development and Testing of the OPLS All-Atom Force Field on Conformational Energetics and Properties of Organic Liquids, J. Am. Chem. Soc. 118 (1996) 11225-11236. doi:10.1021/ja9621760.

31. E. M. Duffy, Ph.D. Thesis, Yale University, 1994. 
32. R. Chitra, P. E. Smith, A Comparison of the Properties of 2,2,2- Trifluoroethanol and 2,2,2-Trifluoroethanol/Water Mixtures Using Different Force Fields, J. Chem. Phys. 115 (2001) 5521-5530.

33. E. K. Watkins, W. L. Jorgensen, Perfluoroalkanes: Conformational Analysis and LiquidState Properties from Ab Initio and Monte Carlo Calculations, J. Phys. Chem. A 105 (2001) 4118-4125.

34. C. M. Breneman, K. B. Wiberg, Determining atom-centered monopoles from molecular electrostatic potentials. The need for high sampling density in formamide conformational analysis, J. Comput. Chem. 11 (1990) 361-373.

35. M. Besnard, T. Tassaing, Y. Danten, J.-M. Andanson, J.-C. Soetens, F. Cansell, A. Loppinet-Serani, H. Reveron, C. Aymonier, Bringing together fundamental and applied science: The supercritical fluids route, J. Mol. Liq. 125 (2006) 88-89.

36. M. Asselian and C. Sandorfy, Anharmonicity and Hydrogen Bonding. The in-plane OH Bending and its Combination with the OH Stretching Vibration, Can. J. Chem. 49 (1971) 1539.

37. O. Holloczki, M. Macchiagodena, H. Weber, M. Thomas, M. Brehm, A. Stark, O. Russina, A. Triolo, B. Kirchner, Triphilic Ionic-Liquid Mixtures: Fluorinated and Nonfluorinated Aprotic Ionic-Liquid Mixtures, ChemPhysChem 16 (2015) 3325-3333. 